\title{
Psychiatric response to the AIDS epidemic in the United States
}

\author{
James Satriano
}

Columbia University, email satrian@pi.cpmc.columbia.edu

\section{The first case of AIDS in a state psychiatric facility was diagnosed in 1983, when a woman in her mid-20s, who had been hospitalised for several months, developed \\ Pneumocystis carinii pneumonia.}

From the early to mid-1990s,

studies began to appear in the literature reporting HIV infection rates among people with serious mental illness. Reported rates of HIV infection varied widely, from a low of $4.0 \%$ to a high of $22.9 \%$ in samples of psychiatrically ill subjects.

\begin{abstract}
n the early 1980s, when the first cases of AIDS were being reported in the gay population and among intravenous drug users, epidemiological research indicated that the disease was both bloodborne and sexually transmitted. Mental health care workers had little concern about infection among people with serious and persistent mental illness, because this population was felt to be too disabled to engage in the sexual or needle-sharing behaviours that put one at risk. Yet the first case of AID $S$ in a US state psychiatric facility was diagnosed in 1983, when a woman in her mid-20s, who had been hospitalised for several months, developed Pneumocystis carinii pneumonia (Cournos et al, 1989). This case was quite shocking to the treatment team, for two reasons: first, AIDS had unexpectedly entered the psychiatric population; and second, the person infected was a woman, when the disease was being reported almost exclusively in men in the United States.
\end{abstract}

\section{The scale of the problem}

From the early to mid-1990s, studies began to appear in the literature reporting HIV infection rates among people with serious mental illness. Reported rates of H IV infection varied widely, from a low of $4.0 \%$ to a high of $22.9 \%$ in samples of psychiatrically ill subjects (Cournos \& McKinnon, 1997). It should be noted that most of these studies were conducted in $\mathrm{N}$ ew York $\mathrm{C}$ ity on in-patient psychiatric units and that the infection rate in the general population of that region at that time was estimated to be approximately $1 \%$.

The wide range of reported rates of infection may be examined in terms of the sub-population of people with psychiatric illness that the studies targeted. The lowest reported rate of infection, 4.0\%, was found among longstay psychiatric patients (Volavka et al, 1991). These patients had been hospitalised for at least a year in a state psychiatric facility and were considered to represent those with the most chronic mental illnesses. Among patients admitted to psychiatric units, excluding those with a primary diagnosis of substance misuse, the rates of HIV infection ranged from $5.5 \%$ to $8.9 \%$ (C ournos et al, 1991; Sacks et al, 1992; Empfield et al, 1993; Meyer et al, 1993; Stew art et al, 1994; Schwartz-Watts et al, 1995). Infection rates among those admitted to special units for the treatment of combined diagnoses of serious mental illness and alcohol/substance use disorders ranged from 16.3\% to $22.9 \%$ (Lee et al, 1992; Susser et al, 1993; Silberstein et al, 1994). Most of these research projects used convenience samples of consecutive admissions over a circumscribed period of time and anonymously tested the patients using waste blood that was drawn at the time of admission. Two studies that examined the HIV detection rate by hospital staff of those who had anonymously tested positive reported that only 28\% (Cournos et al, 1991) and 35\% (Stewart et al, 1994) of those who were found to be HIV positive were identified as being infected during their hospital stay.

A number of interesting findings have been reported in recent years that indicate that mentally ill people are overrepresented among those with HIV infection, that they are not being adequately assessed for H IV risk behaviours and that they are diagnosed later in the course of infection. A study of the HIV Medicaid database in N ew Jersey revealed that over $12 \%$ of that population had a major mental illness (Walkup et al, 1999). Two studies among psychiatric out-patients in N ew York State revealed that less than one-third of the programmes were conducting routine HIV risk assessment (McKinnon et al, 1999; Satriano et al, 1999). A preliminary look at the cost of providing HIV-related medical care to the $\mathrm{N}$ ew York State Medicaid population indicated that it was significantly more costly to provide such care to persons who had a concurrent diagnosis of a major mental illness (Mental H ealth, D rug U se and HIV Medicaid Data Workgroup, 1999). The implication of this finding is that they were much more physically ill with HIV-related disease when diagnosed than those without a mental illness.

\section{Reluctance to assess risk}

In spite of these greatly elevated rates of HIV infection among people with mental illnesses, mental health care workers remain reluctant to assess patients for a history of risk behaviour and to recommend voluntary testing to those found to be at risk. 0 ther than the two studies cited above which found that only about one-third of out-patient mental health care settings routinely screened for H IV risk among new admissions (McKinnon et al, 1999; Satriano et al, 1999), little research has been done to quantify this reluctance, Anecdotal evidence, however, suggests that several factors may come into play. First, there is a resistance to recognising $\mathrm{HIV}$ risk behaviour among mentally ill people. Despite reports of elevated rates of infection and of behaviours that transmit HIV among them, care workers often underestimate the occurrence and frequency of 
these behaviours. Second, some mental health care providers have voiced concerns that merely asking about sexual and drug use behaviour may exacerbate psychiatric symptoms. They believe that broaching these topics is contraindicated in this population. Third, the know ledge that a patient is infected with HIV may raise a number of clinical and ethical dilemmas for the treatment team. D o sexually active or sexually provocative patients infected with HIV represent a risk to others? Is there a duty to warn others of the infected patient's status? Should condoms be provided on in-patientservices? Should HIV status be taken into account in room or ward assignment? Finally, it is frequently true that mental health care providers must assume responsibility for helping patients with serious mental illness to access medical care. Many psychiatrists are reluctant to take on the coordination of the increasingly complex clinical management of H IV infection. In addition, some of the currently prescribed antiretroviral agents have psychiatric side-effects and overlapping toxicities with psychotropic agents, and can also cause significant drug interactions with psychotropic medications (MCD aniel et al, 2000).

\section{Improving the treatment of HIV-positive patients}

O ur current systems of care generally separate treatments for medical conditions, mental health problems and substance misuse, to the extent that the provision of each is overseen by a distinct agency. Individuals needing all of these arenas of service frequently find them poorly coordinated and unavailable at a single site. Although we need to develop a coordinated system of care that is able to integrate treatments, there are still many things that mental health care providers can do to improve the treatment of patients who are HIV infected and to prevent infection in those who are not.

Routine comprehensive HIV risk assessment should be part of all patient intake evaluations for in-patient and out-patient programmes, and this assessment should be repeated at least annually. For those found to be at risk of H IV infection on assessment, counselling for voluntary HIV testing should be conducted and this should emphasise the benefits of early detection and treatment, and the importance of preventing transmission of the virus to others. Risk-reduction and harm-reduction groups should be ongoing and offered to the HIV infected and uninfected alike.

For those testing positive for HIV, mental health care providers should be aware of where patients can go to receive comprehensive medical follow-up and help them to get care. The prescribing of psychotropic medication needs to be coordinated with the provision of antiretroviral medication by the providers of medical care, in order to avoid adverse reactions. Finally, since mental health care staff may see patients frequently, even daily, their role in medication monitoring cannot be overemphasised. Many of the antiretroviral medications must be taken on a strict schedule in order to prevent viral drug resistance. Mental health care providers should be aware of the varied needs of people infected with HIV who also have a mental illness and be ready to meet those needs.

\section{References}

Cournos, F. \& McKinnon, K. (1997) HIV seroprevalence among people with severe mental illness in the U nited States: a critical review. Clinical Psychology Review, 17, 259-269.

Cournos, F., Empfield, M., Horwath, E., et al (1989) The management of HIV infection in a state psychiatric hospital. Hospital and Community Psychiatry, 40, 153-157.

Cournos, F., Empfield, M., Horwath, E., et al (1991) HIV seroprevalence among psychiatric patients admitted to two psychiatric hospitals. American Journal of Psychiatry, 148, 1225-1230.

Empfield, M., Cournos, F., Meyer, I., et al (1993) HIV seroprevalence among homeless patients admitted to a psychiatric inpatient unit. American Journal of Psychiatry, 150, 47-52.

Lee, H., Travin, S. \& Bluestone, H. (1992) HIV-1 in inpatients. Hospital and Community Psychiatry, 43, 181-182.

MCD aniel, J., Chung, J., Brown, L., et al (2000) American Psychiatric Association Practice Guidelines for the Treatment of Patients with HIV/AIDS. Available at the website http:// www.psych.org/clin_res/hivaids32001.cfm. Last accessed 1 August 2002.

McKinnon, K., Cournos, F., Herman, R., et al (1999) AIDS related services and training in outpatient mental health care agencies in N ew York. Psychiatric Services, 50, 12251228.

Mental Health, Drug Use and HIV Medicaid Data Workgroup (1999) Report. N ew York: N ew York State Department of Health, AIDS Institute.

Meyer, I., Cournos, F., Empfield, M., et al (1993) HIV seroprevalence and clinical characteristics of the mentally ill homeless. Journal of Social Distress and the Homeless, 2, 103116.

Sacks, M., Dermatis, H., Looser-0 tt, S., et al (1992) Seroprevalence of HIV and risk factors for AIDS in psychiatric inpatients. Hospital and Community Psychiatry, 43, 736737.

Satriano, J., Rothschild, R., Steiner, J., et al (1999) HIV service provision and training needs in outpatient mental health settings. Psychiatric Quarterly, 70, 63-74.

Schwartz-Watts, D., Montgomery, L. \& Morgan, D. (1995) Seroprevalence of human immunodeficiency virus among inpatient pretrial detainees. Bulletin of the American Academy of Psychiatry and the Law, 23, 285-288.

Silberstein, C., Galanter, M., Marmor, M., et al (1994) HIV-1 among inner city dually diagnosed inpatients. American Journal of Drug and Alcohol Abuse, 20, 101-131.

Stewart, D., Zuckerman, C. \& Ingle, J. (1994) HIV seroprevalence in a chronically mentally ill population. Journal of the $N$ ational M edical Association, 86, 519-523.

Susser, E., Valencia, E. \& Conover, S. (1993) Prevalence of HIV infection among psychiatric patients in a N ew York City men's shelter. American Journal of Public Health, 83, 568-570.

Volavka, J., Convit, A., Czobor, P., et al (1991) HIV seroprevalence and risk behaviors in psychiatric inpatients. Psychiatry Research, 39, 109-114.

Walkup, J., Crystal, S. \& Sambamoorthi, U. (1999) Schizophrenia and major affective disorder among Medicaid recipients with HIV/AIDS in $\mathrm{N}$ ew Jersey. American Journal of Public Health, 89, 1101-1103.
Do sexually active

or sexually

provocative

patients infected with HIV represent a risk to others?

Is there a duty to warn others of the infected patient's status?

Should condoms be provided on inpatient services?

Should HIV status be taken into account in room or ward assignment? 